Artigo original

Hegemonia - Revista Eletrônica do Programa de Mestrado em Direitos Humanos, Cidadania e Violência/Ciência Política do Centro Universitário Unieuro

ISSN: 1809-1261

UNIEURO, Brasília, número 24, Julho a Dezembro de 2018, pp. 65-92.

Recebido em: 1/3/2018

Avaliado em: 23/4/2018

Aprovado em: 3/5/2018

\title{
LA INFLUENCIA DEL SISTEMA DE CARGOS EN LA ACCIÓN COLECTIVA DE LOS BARRIOS DE SAN PABLO DEL MONTE TLAXCALA, MÉXICO
}

Gustavo Amaro Zahuantitla ${ }^{1}$, Efraín Guillen Flores ${ }^{2}$ y Octavio Humberto Moreno Velador ${ }^{3}$

RESUMO: O objetivo deste artigo é demonstrar a influência que a organização tradicional do sistema de posições eclesiásticas tem em ação coletiva em San Pablo del Monte Tlaxcala, no México. Baseia-se na seguinte hipótese: "As características do sistema de carga fornecem aos habitantes do bairro incentivos para participar nos assuntos públicos e privados da comunidade, de forma contínua na discussão e resolução". Do mesmo modo, são geradas estruturas de participação e representação social, como conselhos de cidadãos e assembléias mayordomo, que permitem ao possuidor do cargo, após o termo do prazo, competir por um cargo de representação política. A importância deste estudo é que destaca a importância das interações sociais tradicionais na participação política e, portanto, no desenvolvimento da democracia.

PALAVRAS-CHAVE: Ação coletiva, cidadania, sistema de posições, participação política e democracia.

\footnotetext{
${ }^{1}$ Estudiante de la Maestría en Ciencias Políticas en la Benemérita Universidad Autónoma de Puebla (México).

${ }^{2}$ Estudiante de la Maestría en Ciencias Políticas en la Benemérita Universidad Autónoma de Puebla (México).

${ }^{3}$ Doctor en Sociología y Profesor-Investigador de la Benemérita Universidad Autónoma de Puebla (México).
} 
Artigo original

Hegemonia - Revista Eletrônica do Programa de Mestrado em Direitos Humanos, Cidadania e Violência/Ciência Política do Centro Universitário Unieuro

ISSN: 1809-1261

UNIEURO, Brasília, número 24, Julho a Dezembro de 2018, pp. 65-92.

ABSTRACT: The objective of this article is to demonstrate the influence that the traditional organization of the system of ecclesiastical positions has on collective action in San Pablo del Monte Tlaxcala, Mexico. It is based on the following hypothesis: "The characteristics of the cargo system provide the inhabitants of the neighborhood with incentives to participate in the public and private affairs of the community, in a continuous manner in their discussion and resolution". Likewise, structures of participation and social representation are generated, such as citizen councils and mayordomo assemblies, which allows the possessor of the position, after his term has expired, to compete for a position of political representation. The importance of this study is that it highlights the importance of traditional social interactions in political participation and therefore in the development of democracy.

KEYWORDS: Collective action, citizenship, system of positions, political participation and democracy.

RESUMEN: El presente artículo tiene por objetivo evidenciar la influencia que tiene la organización tradicional del sistema de cargos eclesiásticos en la acción colectiva en San Pablo del Monte Tlaxcala, México. Se parte de la siguiente hipótesis: "Las características que presenta el sistema de cargos proporcionan a los habitantes de los barrios incentivos para participar en los asuntos públicos y privados de la comunidad, de manera continua en su discusión y resolución". Asimismo, se generan estructuras de participación y representación social, como lo son los consejos ciudadanos y asambleas de mayordomos, que permite al poseedor del cargo, después de cumplido su periodo, competir por un cargo de representación política. La importancia de este estudio radica en que pone de manifiesto la importancia de las interacciones sociales tradicionales en la participación política y por ende en el desarrollo de la democracia.

PALABRAS CLAVE: Acción colectiva, ciudadanía, sistema de cargos, participación política y democracia. 
Artigo original

Hegemonia - Revista Eletrônica do Programa de Mestrado em Direitos Humanos, Cidadania e Violência/Ciência Política do Centro Universitário Unieuro

ISSN: 1809-1261

UNIEURO, Brasília, número 24, Julho a Dezembro de 2018, pp. 65-92.

\section{Introducción}

En la mayor parte de la República Mexicana conviven formas tradicionales de organización social regularmente asociadas a la religión que se han mantenido a lo largo del tiempo, y se relacionan con nuevas formas asociativas de carácter político, social y económico.

Es de particular interés dentro de estas estructuras organizativas ligadas a la religión el análisis del denominado "sistema de cargos", asociados a un "santo patrón” o "patrono". Este sistema se encuentra establecido en todo el territorio nacional, sin embargo, en el centro y sureste es donde no ha tenido mayor cambio en sus pautas institucionales.

En el presente trabajo se plantea el estudio del caso del sistema de cargos del municipio de San Pablo del Monte, perteneciente al estado de Tlaxcala y de manera puntual al barrio de Tlaltepango (figura 1), para desarrollarla se tomó en cuenta la organización interna de la comunidad, así como los diversos comités que se derivan de la misma, particularmente la comisión de agua potable.

La primera parte de la investigación se refiere la investigación de aspectos teóricos y empíricos del proceso de urbanización en las comunidades, la presencia del sistema de cargos y la construcción de la acción colectiva entorno a este, La segunda parte de se refiere al análisis de la información recabada en la comunidad, en un nivel particular se analiza el modelo de gestión de agua potable, a raíz de la información recabada por medio de trabajo de campo: aplicación de entrevista a profundidad realizadas a ciudadanos del barrio.

El citado municipio forma parte de la denominada Zona Metropolitana del Valle de Puebla Tlaxcala. Dicha zona ha tenido cambios significativos en los últimos 30 años, a partir de la década de los años 90, inicio una explosión demográfica y por ende desarrollo inmobiliario, lo cual fue producto de las migraciones de habitantes de otros estados y del interior del estado, así como de su crecimiento natural. Algunos de los barrios céntricos de la ciudad de Puebla se vieron afectados con las políticas gubernamentales de expropiación de bienes inmuebles con la intención de crear espacios turísticos. Posteriormente en los municipios conurbados se 
Artigo original

Hegemonia - Revista Eletrônica do Programa de Mestrado em Direitos Humanos, Cidadania e Violência/Ciência Política do Centro Universitário Unieuro

ISSN: 1809-1261

UNIEURO, Brasília, número 24, Julho a Dezembro de 2018, pp. 65-92.

comienzan a construir complejos habitacionales. Esta situación traería consigo el debilitamiento de las formas tradicionales de integración y de acción colectiva.

Para el estudio de caso se parte de la distinción de las esferas pública y privada, para poder comprender de mejor forma la acción colectiva, y las relaciones entre la metrópoli y el barrio, toda vez que el sistema de cargos va de la mano con la organización del barrio, con el espacio donde habitan y conviven de manera directa los ciudadanos. Finalmente se expone el caso de San Pablo del Monte.

II. De lo privado hacia la acción colectiva

La democracia ha sido analizada desde diferentes corrientes del pensamiento, predominando su carácter normativo y a partir de su definición epistemológica: el gobierno del pueblo. En este sentido autores como Sartori (1999), Held (1997) y Sassen (2013) observan a la democracia como una forma de gobierno constituida por instituciones y ordenamientos juridicos generados a través del tiempo que posibilitan la participación política, o bien, como "un conjunto de reglas (primarias o fundamentales) que establecen quien está autorizado para tomar las decisiones colectivas y bajo qué procedimientos" (Bobbio, 2010: 24).

El régimen democrático se consolida a partir de la interacción de los detentadores de los derechos, los ciudadanos que son los sujetos titulares. Estas relaciones se encuentran delimitadas a un área geográfica específica, la nación y la ciudad, y estos son los espacios donde se desarrollan el intercambio de experiencias y de relaciones sociales que influyen en la percepción de los individuos y en la construcción de su cosmovisión, es decir en su identidad, las similitudes o divergencias compartidas. De esta manera la ciudadanía es una construcción de lo individual hacia lo colectivo.

Para Ramírez (2007), Sassen (2013) y Tamayo (2016), la construcción de la ciudadanía es el resultado de un proceso histórico en el que se interrelacionan diversos actores en un espacio determinado, cuyas relaciones determinan las pautas políticas, economicas, sociales y culturales 
Artigo original

Hegemonia - Revista Eletrônica do Programa de Mestrado em Direitos Humanos, Cidadania e Violência/Ciência Política do Centro Universitário Unieuro

ISSN: 1809-1261

UNIEURO, Brasília, número 24, Julho a Dezembro de 2018, pp. 65-92.

que inciden en las instituciones y en la determinación de quien es sujeto a estas. En este sentido se relaciona como una forma de status y de pertenencia. También se pueden observar momentos de expansión o restricción de derechos (sociales, políticos y civiles), por lo cual las características de la sociedad se reconfiguran al tiempo que se forma la acción colectiva.

Kuri (2016: 175) ubica la conformación de la ciudadanía como un desarrollo de tres siglos de transformaciones históricas, sociales, políticas, culturales y urbanas ${ }^{4}$. Este proceso comienza tras las revoluciones burguesas, sobre todo la francesa y el surgimiento de los derechos del hombre y el ciudadano, donde se limitaba el poder del monarca, al paso del tiempo se consolidaría con la creación de un Estado mínimo y la democracia parlamentaria que abarca del siglo XVII al XX, "considerándose dentro de la tradición liberal clásica". Una segunda etapa se caracteriza por la ampliación de derechos sociales y económicos, relacionados con un Estado de orientación social fuerte, los sujetos de estos derechos provienen de movimientos sindicales y campesinos durante el siglo XX. La tercera generación considera a los derechos humanos después de la Segunda Guerra Mundial y el reconocimiento internacional, porque tras el conflicto armado se constituyen las agencias de cooperación internacional con el objetivo de minimizar los conflictos y proteger a los ciudadanos.

La evolución de los derechos está en relación con las transformaciones en la forma de concebir al ciudadano, en un primer momento se muestra la relación súbdito-soberano, sin embargo, tras el paso del tiempo se convierte en una relación entre iguales. Hasta el presente siglo donde la posesión de derechos se ha universalizado y las formas y modos de construcción ciudadana se han desplazado, dando como resultado la integración de nuevos modos de ser ciudadano. Este ha sido un proceso sistemático de adopción de derechos (Bovero, 2002); provocando la transformación de las instituciones políticas y de las prácticas socio culturales de la comunidad donde se integren. Este es el caso de los extranjeros u otros miembros de la comunidad demandantes de apropiarse u obtener nuevas prerrogativas, como el caso de los grupos minoritarios en los que la ciudadanía es la construcción de identidades a partir de las ya existentes

\footnotetext{
${ }^{4}$ Cabe resaltar el origen urbano de la ciudadanía, en la Grecia antigua el ciudadano estaba adscrito a la polis, la ciudadEstado, la cual le daba sentido de pertenencia al territorio al mismo tiempo de la potestad de derechos; que posteriormente seria tomada por la los romanos en la civitas.
} 
Artigo original

Hegemonia - Revista Eletrônica do Programa de Mestrado em Direitos Humanos, Cidadania e Violência/Ciência Política do Centro Universitário Unieuro

ISSN: 1809-1261

UNIEURO, Brasília, número 24, Julho a Dezembro de 2018, pp. 65-92.

(Mouffe, 1999). Desde este enfoque no existe una forma única de ser ciudadano porque en una nación coexisten diferentes formas de identificación y apropiación, por lo que su construcción es divergente y no uniforme. Incluso diversos grupos compiten por las mismas prerrogativas en continua pugna estableciéndose relaciones hegemónicas.

Las relaciones de los ciudadanos en la democracia se basan en los principios de libertad e igualdad, para ejercer sus prerrogativas en consideración a la voluntad de sus intereses y espacios institucionales donde se convierten en cursos de acción. Para Sartori (1999) estas relaciones son asimétricas porque no todos tienen el mismo nivel de influencia, ni todos poseen los medios y/o herramientas para incidir sobre las decisiones y ejercer sus derechos, tras estas restricciones se encuentran las relaciones de desigualdad económicas y de poder político. Cabe resaltar que tanto libertad e igualdad se establecen por medio de la normatividad, como una forma de universalizalización hacia a todos los pertenecientes al Estado. Otra característica de la democracia es la potestad de autonomía en cuanto a "la posibilidad de lo que pueda llegar a ser - en virtud de lo que les es dable, en punto a control de sus creencias y deseos- no en virtud de lo que ha sido" (Pettit, 1999:243). La participación del ciudadano en las actividades democráticas es en virtud de lo que esperan obtener como beneficios o incentivos de cualquier tipo, principalmente sociales.

Para hacer práctica la autonomía es preciso la creación de "un sistema colectivo de toma de decisiones que permita una participación extensa de los ciudadanos” (Held, 2001: 347). Para que este sea democrático ha de considerarse que las decisiones tomadas sean vinculadas a la construcción de una agenda de iniciativas, y es de suma importancia este hecho porque confiere a los participantes la capacidad para construir su entorno.

Para Hirschmann (1986) la integración de los ciudadanos en alguna práctica donde se involucre su participación ha de ofrecer los incentivos necesarios para mantenerse, además de minimizar los riesgos producidos con su integración, tales como conflictos de intereses o incertidumbre respecto a sus decisiones. La generación de la acción social inicia con un grupo de ciudadanos con una o más experiencias adversas o colectivas que se agrupan con un fin en común. Una de las claves para ser efectiva esta voluntad de intervenir en los problemas públicos se halla en las afinidades entre los integrantes del grupo, siendo estas la cultura o problemas en común. Los 
Artigo original

Hegemonia - Revista Eletrônica do Programa de Mestrado em Direitos Humanos, Cidadania e Violência/Ciência Política do Centro Universitário Unieuro

ISSN: 1809-1261

UNIEURO, Brasília, número 24, Julho a Dezembro de 2018, pp. 65-92.

obreros en huelga ejemplifican este tipo de experiencias, la obtención de un mejor salario responde a una situación de vulnerabilidad a los trabajadores identificados con la empresa donde laboran, aunque tenga diferencias respecto a su ideología.

En este sentido la acción colectiva se presenta como una construcción social que resulta de un conjunto de individualidades aglutinadas por un fin común que no necesariamente responda a la mayoría de los involucrados. Aunque en muchas ocasiones no siempre resulta de ese modo, los actores no actúan como se esperaba y ello se debe principalmente a razones de tipo cultural o tradicional. Así se pueden encontrar la continuidad de prácticas de representación política ligadas a lazos familiares, afectivos o de afinidades. Estos se basan en percepciones ancestrales y modelos de organización basados en interacciones y lazos de confianza, donde la autoridad puede estar basada en un consejo de ancianos, sabios o representantes, con procesos institucionalizados de permanencia, salida y toma de decisiones; como es el caso del sistema de cargos. Este tipo de modelos basados en la confianza depende en su mayor parte de la cohesión de los individuos, así como en la cooperación y cumplimiento de los mandatos derivados de las diferentes instancias de representación. En este tipo de fenómenos podemos observar la convivencia de dos formas distintas de concebir lo político y lo público.

La teoría de la democracia presenta a los ciudadanos racionales tomando decisiones apegadas a la maximización de beneficios, sin embargo, el modelo de consejo tradicional transforma la representación basada en el individualismo maximizado y competitivo, en el más sabio o quien se piensa cuenta con los conocimientos necesarios para ese cargo, no solo del orden institucional sino también en las relaciones entre los individuos de la comunidad. Lo político se transforma en un espacio de interacciones sociales de poder, basado en el sentido de pertenencia y de lealtad. Lo público se convierte en la comunidad misma, porque los concejales mantienen una relación directa con los demás miembros y la relación privado - público se difumina. 
Artigo original

Hegemonia - Revista Eletrônica do Programa de Mestrado em Direitos Humanos, Cidadania e Violência/Ciência Política do Centro Universitário Unieuro

ISSN: 1809-1261

UNIEURO, Brasília, número 24, Julho a Dezembro de 2018, pp. 65-92.

2.- De la metrópoli al barrio

La ciudad es el espacio por excelencia donde se desenvuelven los ciudadanos y donde interactúan en función de sus intereses individuales o colectivos, a partir de pautas de identidad o afinidad. Asimismo se vuelve un territorio en disputa, donde cada grupo busca la apropiación de una parte o de un elemento constitutivo de esta, de este modo se produce la disolución de los modos de reproducción de lazos de interacción, fragmentación de la comunidad por segmentos ya sea a través de medios físicos como lo son los limites naturales (barrancas, ríos, montañas, conjuntos habitacionales) o imaginados (preferencia religiosa, sexual o ideológica) (Borja, 2003). Derivado de ello resulta imposible caracterizar una sola forma de ciudad, de concebir a la ciudadanía como una sola, aun cuando la cualidad de ciudadano se presente como igualdad en la posesión de derechos, más bien se pueden observar una diversidad de ciudadanías en relación con la apropiación del espacio.

En la ciudad se vierten distintas formas de reproducción de prácticas culturales desde donde se fraguan luchas por el poder y control entre cada una de las culturas, por lo cual este crisol multicultural representa los límites imaginados del ser ciudadano donde la cohesión radica en la pertenecía o afinidad al territorio (Tamayo, 2016). Por otro lado, la fragmentación territorial de la ciudad se manifiesta en la división de su circunscripción en espacios de menor tamaño donde las interacciones son más estrechas y los lazos de cooperación son de carácter vecinal. A estos espacios se les denomina barrios ${ }^{5}$.

El barrio se considera como un elemento constitutivo de las ciudades, se puede decir que la evolución de la ciudad y del barrio va de la mano. Asimismo, las contradicciones sociales presentes en las dinámicas sociales, políticas y económicas se reflejan en la forma como se constituyen los barrios, así se pueden diferenciar, por su clase social: los marginados o desplazados, migrantes, empresarios; por la pertenencia a un oficio: de los obreros, artistas, etc. De este modo se produce un proceso de identificación asociada a la pertenencia y a la

\footnotetext{
${ }^{5}$ Para Pulido (2016: 430), retomando a Park (1999) el barrio se define como: "la unidad social generadora del espíritu colectivo, que describe sus contornos y su coherencia en la organización interna y externa (...), de sus tradiciones y de su historia particular. Es decir, una realidad autocontenido en la que se vincula el barrio-lugar con una comunidad y que se demarca con unas fronteras claras que establecen la diferencia entre un nosotros y unos ellos".
} 
Artigo original

Hegemonia - Revista Eletrônica do Programa de Mestrado em Direitos Humanos, Cidadania e Violência/Ciência Política do Centro Universitário Unieuro

ISSN: 1809-1261

UNIEURO, Brasília, número 24, Julho a Dezembro de 2018, pp. 65-92.

diferenciación en relación a los habitantes de otros barrios, respecto a sus modos de interacción, de apropiación del espacio y patrones culturales, vinculados también a las relaciones de vecindad y cooperación, producto de la cercanía entre los habitantes del mismo. Las relaciones entre barrios producen choques entre las identidades que cada uno posee, así se observa la predominancia o hegemonía de uno sobre otros, creándose elites o asociaciones colectivas.

El barrio es un espacio territorial que se puede considerar como el lugar de convivencia más cercano a los habitantes de la ciudad, debido a su delimitación espacial en donde las relaciones sociales están determinadas por la vecindad y pertenencia o identificación hacia algún elemento urbano, como una fábrica, la devoción hacia un santo patrón o el área geográfica ${ }^{6}$.

Las dinámicas económicas y políticas influyen de manera preponderante en la sociedad y en sus estructuras, por lo que el espacio territorial es susceptible a estas dinámicas. La globalización y sus repercusiones se reproducen a nivel local como producto del intercambio masivo de información, comunicación y económicos, la economía del país entró en una etapa de globalización, a partir de la década de los 80 y se profundizó con la firma de tratados comerciales que trajeron consigo procesos de privatización de empresas paraestatales, el ingreso de capital extranjero en todos los sectores de la economía, así como el desmantelamiento paulatino de las cadenas de producción y la modificación en las dinámicas sociales propias de cada sector afectado. El imaginario colectivo también se modificó, pasó de pensar en lo local a ser parte de lo global, y el territorio se configuró como el lugar donde se correlacionan los agentes locales y globales. Al mismo tiempo, la comunicación se reproduce a través de medios digitales, donde no existen fronteras o tiempos que impidan la circulación de información.

En el caso de la zona metropolitana Puebla - Tlaxcala, se observa la constitución barrial a partir de los oficios, la industria y principalmente de la devoción a un santo patrón. En esta zona geográfica, los barrios han sido afectados por procesos de globalización e intervención de capital extranjeros en el marco de las políticas neoliberales que han derivado en el cambio de algunas prácticas dentro de los barrios. De acuerdo con Licona, Espinoza y Villalobos (2016), el

\footnotetext{
${ }^{6} \mathrm{La}$ industrialización del país trajo consigo la aglutinación de poblaciones alrededor de empresas o parques industriales, y como consecuencia de este fenómeno, surgieron barrios de trabajadores, prestadores de servicios hacia esas compañías. Como el caso del barrio la Fama en la ciudad de México, en donde la identidad social y la evolución del barrio se encuentra ligado a la fábrica. Véase (Kuri Pineda, 2015).
} 
Artigo original

Hegemonia - Revista Eletrônica do Programa de Mestrado em Direitos Humanos, Cidadania e Violência/Ciência Política do Centro Universitário Unieuro

ISSN: 1809-1261

UNIEURO, Brasília, número 24, Julho a Dezembro de 2018, pp. 65-92.

reconocimiento de los barrios a partir de un santo patron data de 1548, como parte de un proceso de colonización y evangelización de los pueblos originarios. Se pretendía crear estructuras sociales en torno a las celebraciones y patrones eclesiásticos, orientados a establecer al santo como el protector de la comunidad. Bonfil considera que la organización del barrio y de la comunidad local son el resultado de "un orden colonial" (1973:175). A partir de estos elementos se observa al barrio como una unidad de integración social con territorio, cultura, identidad y organización propia.

En la ciudad de Puebla se presentó un fenómeno de expropiación de tierras en 1993 cuando 22.4 hectáreas del centro de la ciudad de Puebla, que incluye los barrios de Analco, La Luz y El Alto, se vendieron a agentes privados. Estos terrenos con sus barrios se caracterizaron históricamente por estar habitados por trabajadores e indígenas provenientes de otros municipios metropolitanos, asimismo las dinámicas sociales estaban ligadas a las fabricas aledañas, los comercios y mercados cercanos. El proceso de expropiación tenía como finalidad la creación de un corredor turístico, caracterizado por un centro comercial, hoteles, restaurantes y estacionamientos, construidos sobre las ruinas de fábricas, vecindades y restos del antiguo convento de San Francisco. Los habitantes del barrio se organizaron para defender sus propiedades; sin embargo, tras una serie de disputas internas, se desintegraron (Gómez, 2008). Este proceso de intervención estatal para incentivar la inversión extranjera sobre la ciudad y los barrios se reprodujo de manera constante en municipios de la zona metropolitana, lo que ha repercutido en los procesos de construcción del espacio territorial, social, de la concepción de la ciudad, por ende, de ciudadanía a través de la apropiación de identidades y derechos.

III. El sistema de cargos en San Pablo del monte y la acción colectiva

En la región Puebla- Tlaxcala la forma de organización básica al interior de los municipios es el barrio, el cual de manera preponderante está orientado al culto de un santo patrono, particularmente en el municipio de San Pablo del Monte —el cual se encuentra ubicado al sur del Estado de Tlaxcala_-, la presencia de tal núcleo básico de organización es común al interior, 
Artigo original

Hegemonia - Revista Eletrônica do Programa de Mestrado em Direitos Humanos, Cidadania e Violência/Ciência Política do Centro Universitário Unieuro

ISSN: 1809-1261

UNIEURO, Brasília, número 24, Julho a Dezembro de 2018, pp. 65-92.

tal como se muestran en cada uno de sus barrios ${ }^{7}$. El municipio desde 1997 forma parte de la cuarta zona metropolitana, hecho que fue formalizado en $2004^{8}$. Del fenómeno urbanizador se generaría una serie de cambios reflejados en las características socioeconómicas del municipio, fenómeno que con el paso del tiempo motivaría el deseo del cambio de denominación de la cabecera municipal en el año 2016, donde se solicita el cambio de nombre de villa Vicente guerrero a Ciudad San Pablo del Monte (CONGRESO, 2016).

San Pablo del Monte es un municipio del estado de Tlaxcala que cuenta con 77,242 habitantes, después de la capital es el segundo municipio con mayor número de habitantes. Colinda "al norte con los municipios de Tenancingo, Papalotla, Mazatecochco, Acuamanala y Teolocholco; al este con el municipio de Teolocholco y el estado de Puebla; al sur con el estado de Puebla; al oeste con el estado de Puebla y los municipios de Tenancingo y Papalotla” (INEGI, 2015).

El municipio está constituido por una cabecera municipal denominada Ciudad San Pablo del Monte doce presidencias de comunidad, o barrios: "San Sebastián, San Bartolomé, San Pedro, Tlaltepango, La Santísima, San Miguel, San Nicolás, El Cristo, Santiago, De Jesús, San Cosme y San Isidro Buensuceso" (Tlaxcala, 2015: 3). En total el municipio tiene una extensión territorial de 63,460 kilómetros cuadrados que representan el 1.57\% del territorio del estado (INEGI, 2009).

\footnotetext{
${ }^{7}$ La constitución del Estado de Tlaxcala en su artículo primero en su párrafo segundo declara el origen indígena de la entidad, por lo cual reconoce sus formas de organización y diversas expresiones contenida en las comunidades, hecho por el cual a las presidencias de comunidad se les dota de recurso Estatal y Federal para lograr las metas de una vida colectiva. Para los habitantes del municipio de SPM la denominación de las comunidades al interior del mismo corresponde al termino de barrios; sin embargo, tal denominación dista de las disposiciones contenidas de acuerdo a la Ley Municipal del Estado de Tlaxcala, la cual en su artículo séptimo establece las categorías de la clasificación de la población, estos basado en elementos socioeconómicos; en tal disposición no se menciona la categoría de barrio, solo se consideran elementos como: ciudad, villa, colonia, ranchería; tal hecho evidencia la necesidad del término barrio dentro de la legislación, contando no solo para ello características socioeconómicas, sino abordando aspectos históricos y culturales; por otro lado para el caso del municipio, a este corresponde analizar el caso para cada una de las comunidades, de manera que si cuentan con las características de barrio, ciudad, villa o ranchería, estas deban ajustarse a sus nuevas circunstancias; tal elementos solo representaría un cambio de denominación, el cual tendría mínima y lenta influencia al interior de las comunidades.

${ }^{8}$ En la agenda de Estadística del Agua en México / CONAGUA (2016) se manifiesta que proceso por el cual se realiza la delimitación de las zonas metropolitanas sucedió en 2004, año en el que un grupo conformado por la Secretaria de Desarrollo Social, el Consejo Nacional de Población y el Institutito Nacional de Estadística e Informática, identificaron 55 zonas metropolitanas a nivel nacional donde destacan las cuatro con mayor población: Valle de México, Guadalajara Monterrey y Puebla-Tlaxcala.
} 
Artigo original

Hegemonia - Revista Eletrônica do Programa de Mestrado em Direitos Humanos, Cidadania e Violência/Ciência Política do Centro Universitário Unieuro

ISSN: 1809-1261

UNIEURO, Brasília, número 24, Julho a Dezembro de 2018, pp. 65-92.

En cuanto a la población económicamente activa para el INAFED (2017), en 2015 había 57,663 personas activas, 30,565 se encontraba laborando, de estas 20,431 son hombres, 2,026 se dedicaban a alguna profesión, funcionarios o administrativos, 1,134 a labores agrícolas, 12,035 trabajadores industriales, y 5,062 al comercio. En el caso de las mujeres, el total es de 10,134, de las cuales 1361 ocupadas en actividades profesionales, funcionarios o administrativos, 108 en el campo, 3,333 en la industria y 5214 al comercio (INEGI, 2016). En las actividades industriales destaca la fabricación de ropa y talleres de talavera; por lo regular administrados por familias.

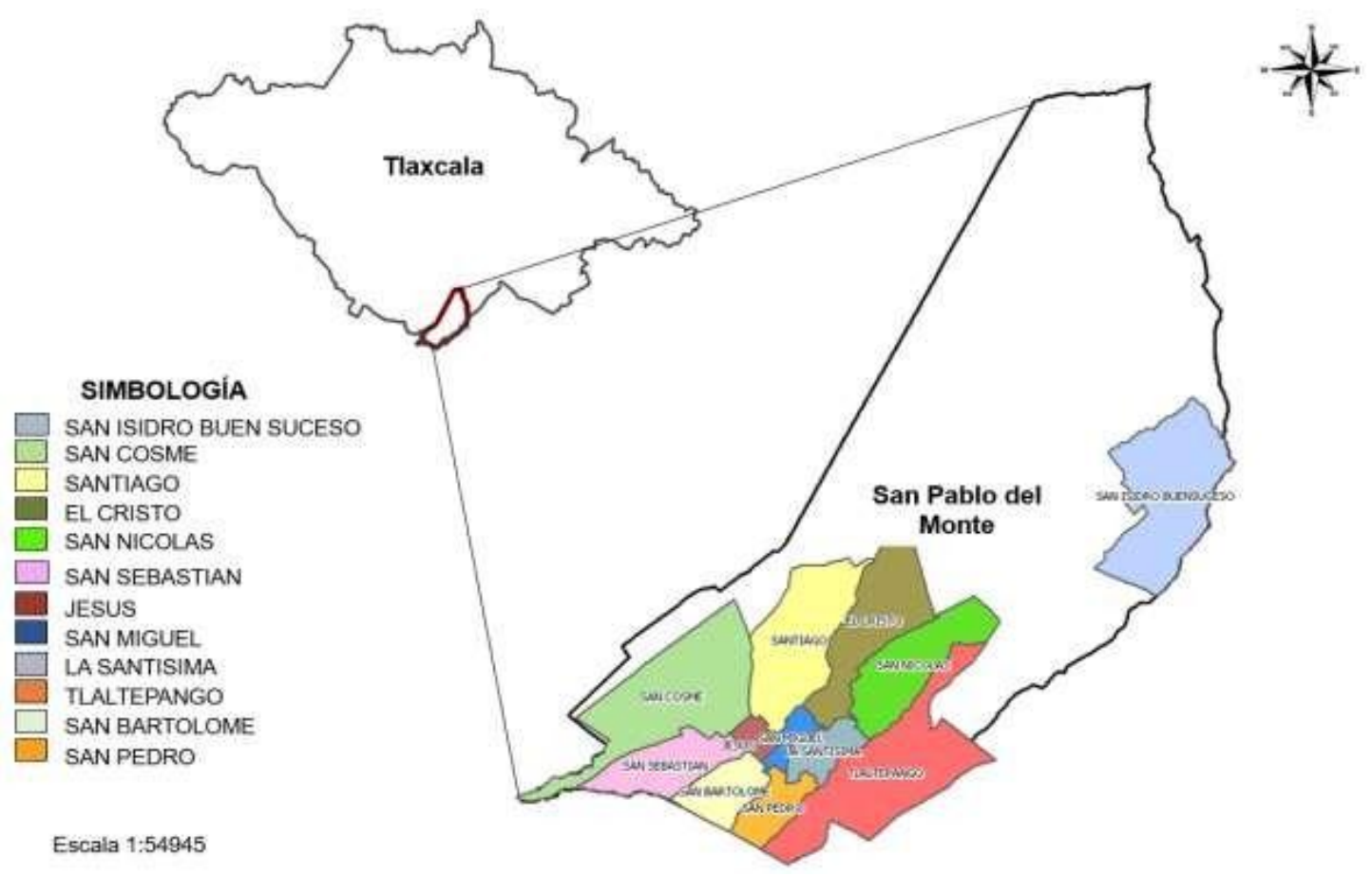

Figura 1. Barrios de San Pablo del Monte. Tomado de Rivera (2016:51).

Pese al proceso de urbanización que se puede observar existen aspectos que se conservan al interior del municipio, por ejemplo: la práctica ritual y parental. Ya autores como Bonfil, G. (1974); Nutini, H. y Barry (1974); Portal, (1997); Korsbaek, (1996) y González (2011), han documentado dichos aspectos que se expresan frente al proceso de urbanización. La organización tradicional ha mostrado resistencia y adecuación, y pasa a ser observada no sólo como una organización propia de los espacios rurales, sino como organizaciones presentes de 
Artigo original

Hegemonia - Revista Eletrônica do Programa de Mestrado em Direitos Humanos, Cidadania e Violência/Ciência Política do Centro Universitário Unieuro

ISSN: 1809-1261

UNIEURO, Brasília, número 24, Julho a Dezembro de 2018, pp. 65-92.

los espacios urbanos, dinamizando la vida de la comunidad en sus aspectos, económicos, políticos y sociales.

La vida de los barrios gira en torno a un elemento constitutivo que es la parroquia o capilla, en las cuales se forma el llamado sistemas de cargos (SC). Este se compone por "un número de oficios que están claramente definidos como tales, que se turnan entre los miembros de la comunidad, quienes asumen un oficio por un período corto de tiempo, después del cual se retiran a su vida normal" (Korsbaeck, 1996:9). El sistema de cargos es integrado por miembros del barrio, los cuales son encargados de los cuidados y celebraciones del templo y particularmente de la celebración del santo patrono. Un autor como González, (2011) manifiesta que el sistema de cargos es integrado de manera heterogénea, y se alimenta con mecanismos de participación que permiten la interacción de los miembros en diversos escenarios posibles - recolectas, celebraciones y comisiones-, todo por medio de un conjunto de rotaciones mediante las cuales se fomenta la mayor participación posible de los integrantes de la comunidad.

Comenta Espinoza (2006), respecto del barrio y la religión, que lo religioso al interior de las comunidades no se limita a la experiencia subjetiva y creencia devota del hombre, sino que está también afianza a las familias en el territorio donde interactúan y recrean a diario en relación con los otros, siendo así una institución social que no implica la sola ligazón con la fe sino también en un vínculo social en cuanto construcción colectiva.

De ambas consideraciones se permite observar una dimensión religiosa en primer momento, y en uno posterior como el generador de espacios de interacción que parten de un centro religioso en común, que permiten generar identidad y diferenciación respecto a las diferentes comunidades con las que interactúan.

Este fenómeno se puede observar en cada una de los barrios del municipio de San Pablo del Monte donde existe SC en cada capilla o parroquia, la categoría que guarda la cabecera municipal y el barrio de Tlaltepango es de parroquias y las demás son capillas ${ }^{9}$. Tlaltepango se encarga de

\footnotetext{
${ }^{9}$ De acuerdo al Código de Derecho Canónico: es una determinada comunidad de fieles constituida de modo estable en la iglesia particular, cuya cura pastoral bajo la autoridad del obispo diocesano, se encomienda a un párroco, como su propio pastor...siendo el lugar donde se administran los sacramentos y se atiende espiritualmente los fieles de una feligresía (CDC: 515-519).
} 
Artigo original

Hegemonia - Revista Eletrônica do Programa de Mestrado em Direitos Humanos, Cidadania e Violência/Ciência Política do Centro Universitário Unieuro

ISSN: 1809-1261

UNIEURO, Brasília, número 24, Julho a Dezembro de 2018, pp. 65-92.

brindar servicios eclesiásticos — característica que permite la distinción entre parroquia y capillas - a las comunidades de La Santísima y San Pedro. Para el caso de los servicios sacramentales de los barrios de San Nicolás, San Sebastián, San Bartolomé, El Cristo, San Miguel, De Santiago, De Jesús y San Cosme, estos pertenecen a la parroquia de San Pablo Apóstol ubicada en la cabecera del municipio. Para el caso de San Isidro Buen suceso, por su lejanía del centro del municipio, de manera individual se encarga de proveerse de los servicios que eclesiásticos, guardando su categoría de capilla aun cuando sus funciones comienzan a ser las de una parroquia.

El sistema de cargos en cada barrio guarda una jerarquía histórica. La adoración que realizan a un santo patrono, comenta Portal (1997: 132), es un marcador de fronteras simbólicas en dos niveles: en el aspecto histórico, pues su presencia determina un momento en que la colectividad comenzó a existir como tal, y en el ámbito social al convertirse en un referente de distinción frente a los otros, "su fuerza como referente de identidad colectiva implica una posición diferenciada frente a otras comunidades de la región; es decir, delimitar un contexto social comunitario que facilita establecimiento de fronteras — reales y simbólicas - entre el afuera y el adentro" .

La vida en comunidad reafirma un sentido en común y tal como lo menciona Portal (1997) formula fronteras; las cuales sustentan la vida en comunidad y son reflejadas en las prácticas cotidianas, mismas que se encuentran en tres niveles que le permiten diferenciarse de los demás, en un primer momento al interior de la comunidad, posteriormente frente a las demás comunidades y finalmente frente a la ciudad; tal proceso genera diversos escenarios de interacción de organizaciones, al interior también se encarga de interactuar con organizaciones políticas y sociales, lo que permite debatir temas de interés común entre los grupos religiosos con los que interactúa, por ejemplo con: testigos de jehová, cristianos mormones, luz del mundo, evangélicos y agregando a las hermandades (Prisco, 2016).

En cuanto a las interacciones políticas, se puede observar a las reuniones de fiscalía como un escenario para escuchar a los diversos aspirantes políticos, en las cuales existe mayor aceptación gracias a la participación en el SC o diversos comités de la comunidad, ya que se considera que 
Artigo original

Hegemonia - Revista Eletrônica do Programa de Mestrado em Direitos Humanos, Cidadania e Violência/Ciência Política do Centro Universitário Unieuro

ISSN: 1809-1261

UNIEURO, Brasília, número 24, Julho a Dezembro de 2018, pp. 65-92.

haber sido parte de las tales comisiones permite tener un mejor conocimiento de los temas del barrio.

En su aspecto social el SC dinamiza escenarios de participación entre los habitantes del barrio, esto por medio de la práctica ritual de las festividades del calendario ritual, — vírgenes, santos y en particular del santo patrono-, comités de barrio y reuniones anuales. Además, las celebraciones generan formas de parentesco ritual — padrinos, compadres ${ }^{10}$ — que amplían el margen de interacción de los miembros de la comunidad para tratar temas particularesbúsqueda de trabajo, acompañamiento de las prácticas de ciclo de vida u actividad que requiera responsabilidad - o en común — servicios públicos, administración de la presidencia de comunidad y forma de relacionarse frente al municipio-.

Esta preponderancia del SC como organización local en cada uno de los barrios del municipio se ha visto fortalecida por el cumplimiento de las tareas, lo que ha fortalecido la organización y ha dado paso a consolidar un espacio de interacción y coexistencia común que permiten generar una identidad diferenciadora de los demás barrios del municipio. Además de ello, un factor importante es la manera de estar integrada por miembros de la comunidad quienes toman parte de relaciones particulares y colectivas, actitud que ha devenido en la búsqueda de un bien común $^{11}$. El cual es parte de un proyecto de vida que se concluye en el reconocimiento hacia con los demás.

El SC desde una perspectiva sociológica sería considerado como una organización, con frontera relativamente identificable, con un orden normativo, niveles de autoridad, sistema de comunicación y de coordinación. Existe de manera continua en un ambiente y se involucra en actividades orientadas a un conjunto de metas, los cuales, de un buen funcionamiento de los

\footnotetext{
${ }^{10}$ Comenta Nutini y Bell (1989: 347) que "El compadrazgo no solo tiene aspectos individuales o egocéntricos, que afectan a la triada básica, sino que también tiene aspectos colectivos y exocéntricos que pueden unir por lazos permanente o semi permanentes grupos a veces bastante grandes de individuos y con funciones importantes dentro de la organización comunal. Cuando sucede, el compadrazgo se puede considerar como el complemento o equivalencia funcional del parentesco e instituciones realizadas".

11 De acuerdo a Recasens (1983) como el mayor número de bienes determinados por los individuos, el cual en su repertorio integra una serie de condiciones sociales que faciliten beneficios para los mismos, en esta consideración se muestra la presencia de un complejo número de bienes objetivos, que integran la noción del bien común: la paz social, la soberanía del Estado, orden público, salud pública, medio ambiente, sistemas de recursos naturales etc.
} 
Artigo original

Hegemonia - Revista Eletrônica do Programa de Mestrado em Direitos Humanos, Cidadania e Violência/Ciência Política do Centro Universitário Unieuro

ISSN: 1809-1261

UNIEURO, Brasília, número 24, Julho a Dezembro de 2018, pp. 65-92.

diversos aspectos organizacionales, logran incidir en los miembros, su organización misma y la sociedad (Hall,1996). La participación en el SC implica ser sujeto a un proceso de socialización organizacional, esto es que los individuos que participan en organizaciones solo cuentan con un pequeño cumulo de información con el que emprende su participación en la organización, y a partir de la interacción con toda la organización logra comprender todo el conjunto. La organización del SC al estar integrada por miembros de la comunidad procura buscar beneficios comunes como parte de un ethos de la sociedad. Sin embargo, es necesario recordar que toda organización es sujeta al cambio, la influencia de la globalización como factor de modificación de las prácticas al interior es constante, por lo que es necesario cuestionar la naturaleza de los objetivos y la manera de trabajar en la actualidad del SC.

La organización ha representado en muchas ocasiones la aspiración de individuos que buscan por un lado el bienestar colectivo y por otro el legitimarse colectivamente en aras de un beneficio privado. González (2011) plantea que los integrantes pueden cambiar sus objetivos comunales, por ejemplo, cuando la participación de los individuos tiene como objetivo el lograr un cargo de elección popular, pero este puede ser castigado por la comunidad al no realizar el trabajo común como parte del desarrollo de cargos. Los objetivos pueden ser propuestos por los miembros de la organización, derivado de un consenso en el mejor de los casos u originado por una pequeña minoría, lo que puede afectar al fin original de la organización. Tales cuestiones de acuerdo a Somuano (2011) han representado una constante pregunta ¿quién participa en las organizaciones y cuáles son sus fines?

El SC de Tlaltepango muestra al interior del municipio expresiones de interacción constante, respondiendo a cuestiones parentales, políticas y sociales. En específico nos referiremos en adelante al caso del acceso al agua potable en la comunidad de Tlaltepango, sujeta a diversos momentos de participación en los cuales el desempeño tiene que ser optimo y en beneficio colectivo para así legitimarse frente a la comunidad. Esta comisión cobra importancia máxime cuando los encargados desean posteriormente obtener un cargo de elección popular, como podría ser la presidencia de la comunidad. 
Artigo original

Hegemonia - Revista Eletrônica do Programa de Mestrado em Direitos Humanos, Cidadania e Violência/Ciência Política do Centro Universitário Unieuro

ISSN: 1809-1261

UNIEURO, Brasília, número 24, Julho a Dezembro de 2018, pp. 65-92.

La gestión de recursos de uso común en la comunidad de Tlaltepango

La gestión del sistema de agua potable al interior de la comunidad corre a cargo de la comisión de agua potable, la cual cuenta con su oficina principal en la presidencia de comunidad. Recientemente la investigación de Rivera, Hernández, Ocampo y Ramírez (2016) han documentado las características de la estructura de dichos comités, los cuales se componen de tres áreas básicas, el área directiva, integrada por el director, el secretario, tesorero y vocales; la parte administrativa la conforma una secretaria, y en la parte operativa un fontanero.

El barrio de Tlaltepango cuenta con dos pozos de extracción a 150 metros de profundidad, los cuales distribuyen el recurso por medio de una red de distribución, además es apoyada por una serie de tanques superficiales que generan el acceso al recurso de manera diaria durante las 24 horas del día. La elección de dicho comité se realiza de manera anual similar al SC, la selección de personas se realiza en el mes de noviembre, en un primer momento la formación es de modo voluntario y de no ser así se realiza una selección a partir de los propios integrantes que conforman el comité, estos buscaran su remplazo o al tener conocimiento de personas que no han participado se encargan de anotar los nombres de quienes faltan por participar, posteriormente serán notificados por la presidencia de comunidad.

La duración del cargo es de un año, no es remunerado y en caso de adoptar el compromiso y no cumplir con él, puede ser causa suficiente para prohibirle el acceso al servicio y serle muy difícil el acceder legítimamente a otros cargos en la comunidad. Esto es algo que a simple vista pudiera contravenir el derecho de acceso al agua y el derecho a ejercer los derechos civiles y políticos, pero que frente al continuo de la comunidad es su forma tradicional de funcionamiento.

La forma de organización ha incidido para que el comité pueda contar con un padrón de usuarios actualizado, pudiendo derivar en mejoras, tal como menciona Rivera, et al (2016) donde a partir de conocer el número de usuarios es posible establecer costos, tarifas justas, accesibles, además de poder contar con una mejor atención y detectar la existencia de conexiones clandestinas que pueden regularizarse. La tarifa del servicio es de 60 pesos de manera mensual e independiente de la cantidad consumida y familias que habiten la vivienda. El cobro del servicio se realiza por 
Artigo original

Hegemonia - Revista Eletrônica do Programa de Mestrado em Direitos Humanos, Cidadania e Violência/Ciência Política do Centro Universitário Unieuro

ISSN: 1809-1261

UNIEURO, Brasília, número 24, Julho a Dezembro de 2018, pp. 65-92.

dos vías, la primera en las oficinas de la presidencia y otra por medio de las visitas a viviendas censadas, esto genera un porcentaje de recaudación del $60 \%$ de 3.950 usuarios registrados, de un total de 8.563 habitantes (Rivera, et al 2016).

La comisión de agua potable es una organización creada e integrada por los miembros de la comunidad, los cuales se encargan de realizar las actividades de gestión del recurso. La gestión del agua en la comunidad de Tlaltepango se origina en los años sesenta a raíz de la primera excavación que se realiza para extraer agua; en este momento de creación institucional local, la nueva conformación tendría influencia del SC al ser una forma de organizarse longeva y legitimada por el barrio en torno al santo patrono "el cristo resucitado".

La adopción de una estructura previa para la gestión de bienes comunes se debía en un principio al funcionamiento demostrado al interior del barrio, por la responsabilidad que representa el integrar un SC derivando en la eficacia de la misma. Sin embargo, dicho proceso no sería exclusivo del manejo del agua, además, se encontraba marcado en aspectos rituales de la comunidad - fiscales, mayordomos, mahuiltomos, festejos y fiestas patrias -, lo que generaría una escalera de cargos, los cuales ser asumidos por los miembros de la comunidad para ser legitimados como parte de tal y su proyecto conjunto entorno al santo patrono.

Esto se observa particularmente en las personas que deseen acceder a la presidencia del barrio, consuetudinariamente se necesita haber participado en algunas de las comisiones, ya sea de agua potable, fiscales, festejos, fiestas patrias o mayordomía. Aun cuando no es del todo obligatoria, es mal visto si no se ha participado al interior de la comunidad, lo cual genera pocas simpatías políticas y electorales.

De esta manera, la pertenencia a un grupo que busca un bien común, genera que las obligaciones como las contribuciones económicas más que dinero sean un hecho por el cual reafirman vínculos, interés en su pueblo y pertenencia a la comunidad, ya que cada vez que se da dinero se reitera que se hace parte de una colectividad ante la cual se deja constancia de que también colabora (Espinoza, 2006).

La importancia de adoptar diversas comisiones previas a determinados cargos radica en la experiencia y conocimiento del entorno que se necesita para orientar las acciones al bienestar 
Artigo original

Hegemonia - Revista Eletrônica do Programa de Mestrado em Direitos Humanos, Cidadania e Violência/Ciência Política do Centro Universitário Unieuro

ISSN: 1809-1261

UNIEURO, Brasília, número 24, Julho a Dezembro de 2018, pp. 65-92.

colectivo. Asumir alguna de las comisiones y en particular la comisión de agua potable exige que el desempeño de los participantes sea el adecuado, no solo es la participación en un cargo, es la legitimación para otros más, por lo cual las actividades y resultados generados en cada uno de ellos deben ser los mejores.

La influencia del SC en Tlaltepango surge a raíz de la vida alrededor de un santo que ha generado una identidad propia al interior, frente a los demás barrios y frente a la capital poblana. Así mismo el SC se encuentra dividido en diversos niveles, en una primera instancia para ser considerado mayordomo es necesario ser integrante del grupo de Mahuiltomos que se encargan de auxiliar a los mayordomos que se encuentran en funciones - servir comida a la gente durante las celebraciones es su principal tarea-. Otro grupo es el conformado por los fiscales, quienes se encargan de apoyar a los objetivos que se fije el templo, infraestructura principalmente. Finalmente, el grupo de mayordomos que es liderado por el titular del Santo de la comunidad "Cristo resucitado", ellos son los encargados del cuidado del templo y de la celebración de las festividades.

El cargo de fiscal no es considerado necesario para ser mayordomo del santo patrono, anteriormente para asumir la mayordomía del santo patrono se requería de haber sido parte de los diversos comités, pero aun cuando ya no es del todo necesario, de manera consuetudinaria es lo óptimo si se quiere tener posibilidades de competir a un cargo de elección popular. El caso particular del sistema de cargos perteneciente a la parroquia de Tlaltepango cuenta con características que la hacen diferente, en primer lugar, por tener la categoría de parroquia y brindar servicios eclesiásticos a otras comunidades; y en segundo lugar por el elevado número de habitantes que posee. La principal actividad económica es la maquila de ropa, comercios y servicios, su preponderancia en la región ha generado conflictos con el ayuntamiento de la cabecera municipal al igual que con el SC de la cabecera municipal. La comunidad ha desarrollado una identidad propia, la cual se distingue de la de San Pablo, con quien guarda su mayor relación en lo económico. Esta identidad entorno a su comunidad ha permitido que se dinamicen aspectos comunes por medio de los integrantes, quienes ven el SC el espacio de influencia común. 
Artigo original

Hegemonia - Revista Eletrônica do Programa de Mestrado em Direitos Humanos, Cidadania e Violência/Ciência Política do Centro Universitário Unieuro

ISSN: 1809-1261

UNIEURO, Brasília, número 24, Julho a Dezembro de 2018, pp. 65-92.

La categoría de parroquia, el número de población y la actividad económica permitieron que con el tiempo la comunidad aspirara a una autonomía a respecto a otros servicios que le brindaba el municipio. Sin embargo, la relación con la cabecera municipal es inherente, en primer momento por los servicios y recursos que se brinda a dicho barrio, posteriormente por ubicarse en una zona limítrofe en el cual el conflicto de límites territoriales con Puebla capital es constante, lo que genera que el municipio ponga especial atención a este barrio.

Respecto del éxito obtenido en el acceso del recurso, en un análisis de la comisión formada por la comunidad de Tlaltepango, se evalúa criterios propuestos para una buena gestión, esto como parte de la visión de alterna a la gestión de mercado y publica, les permite concluir comparado frente a los principios propuestos por Ostrom (1990), que la situación de dicha forma de gestión es frágil (Rivera et al, 2017). Esto ha sido representado por la tabla 3.1 a partir de la apreciación de dichos autores y del estudio del caso particular de la comunidad. Sin embargo, tal conclusión no retoma la influencia del SC en dicha forma de organización, generando con ello un panorama incompleto del análisis de la gestión, si bien concluyen que esta es frágil, no consideran aspectos de la vida del barrio que han influido en este como es el SC.

La importancia del SC ha permitido generar espacios de interacción que permiten atender temas en común mediante la participación del mayor número de miembros, aunado a ello las formas de apropiación de recurso han influido en una delimitación territorial y étnica respecto del territorio además de la practica ritual —y que se observa en los conflictos con otras comunidades respecto del recurso-, reconociendo a quienes son parte de los beneficiarios por el trabajo realizado al interior de la comunidad.

Pese a la apreciación de Rivera et al (2017) sí consideramos la influencia del SC en la comisión de agua potable, encontramos la formación de varios principios más. Sin embargo, no se puede evitar el carácter negativo en algunas, el cual es sumado a los intereses privados y contextuales que terminan por complicar el objetivo de la comisión, catalogando a está como un organismo de larga duración, la cual de manera frágil realiza la gestión, esta como parte de un ciclo de cargos al interior de la comunidad, lo que ha permitido su conservación a pesar de que algunas características no sean del todo apegadas a las propuestas por Ostrom. 
Artigo original

Hegemonia - Revista Eletrônica do Programa de Mestrado em Direitos Humanos, Cidadania e Violência/Ciência Política do Centro Universitário Unieuro

ISSN: 1809-1261

UNIEURO, Brasília, número 24, Julho a Dezembro de 2018, pp. 65-92.

El éxito obtenido hasta ahora muestra dos factores importantes. Por un lado, al identificarse con un SC se origina el auto-reconocimiento como miembro de la comunidad y su influencia en el entorno lo que permite incentivar la participación; - por otro lado, muestra la constante participación de aspirantes a cargos de elección popular que buscan ser parte de las diversas comisiones para legitimarse colectivamente, en las cuales se espera un correcto desarrollo del cargo ya que de lo contrario se estaría cerrando las oportunidades de apoyo ante la comunidad. Finalmente es necesario mencionar que parte del funcionamiento se debe a la existencia de una interacción de diversos comités de comunidad, basados en la confianza y de los cuales tras una constante repetición o participación en las prácticas rituales y parentales se genera la información necesaria para la atención de temas en común.

\begin{tabular}{|c|c|}
\hline Principios para el manejo de ruc & Comisión de agua potable \\
\hline Limites definidos & $\begin{array}{l}\text { Existe un conocimiento de los usuarios del } \\
\text { servicio, desarrollando con ello un padrón } \\
\text { actualizado. No existe conocimiento } \\
\text { completo de la cantidad de agua de la que } \\
\text { dispone la comunidad implicando una posible } \\
\text { explotación, al no limitar el acceso a dicho } \\
\text { recurso. }\end{array}$ \\
\hline $\begin{array}{l}\text { Coherencia de reglas de apropiación y } \\
\text { provisión }\end{array}$ & $\begin{array}{l}\text { Existe una distribución adecuada en la } \\
\text { comunidad a un precio módico. Por otro lado, } \\
\text { el cobro no depende de la cantidad consumida } \\
\text { - casa habitación o fabrica- o el número de } \\
\text { familias que habitan por vivienda, lo que } \\
\text { implica un grado discrecional de explotación } \\
\text { de ciertos sectores. }\end{array}$ \\
\hline
\end{tabular}


Artigo original

Hegemonia - Revista Eletrônica do Programa de Mestrado em Direitos Humanos, Cidadania e Violência/Ciência Política do Centro Universitário Unieuro

ISSN: 1809-1261

UNIEURO, Brasília, número 24, Julho a Dezembro de 2018, pp. 65-92.

\begin{tabular}{|c|c|}
\hline Arreglos de elección colectiva & $\begin{array}{l}\text { Las modificaciones a las reglas operativas se } \\
\text { realizan durante asambleas de comisión o si lo } \\
\text { amerita una asamblea de barrio, lo que } \\
\text { permite contar con un espacio donde se } \\
\text { diriman los conflictos derivados de la gestión. }\end{array}$ \\
\hline Monitoreo & $\begin{array}{l}\text { Los miembros de la comisión se encargan de } \\
\text { la vigilancia y atención de demandas } \\
\text { relacionadas al agua potable, además rinden } \\
\text { cuentas a la comunidad. No cuentan con } \\
\text { información completa respecto a la extracción } \\
\text { del bien. }\end{array}$ \\
\hline Sanciones graduales & $\begin{array}{l}\text { No existe una sanción de acuerdo a la } \\
\text { gravedad de la falta cometida, está es de } \\
\text { manera unilateral y suele violar el derecho al } \\
\text { acceso del agua. Lo impuesto como sanción } \\
\text { no se refleja en beneficio de los miembros que } \\
\text { cumplen las reglas. }\end{array}$ \\
\hline Mecanismos para la solución de conflictos & $\begin{array}{l}\text { Existen instancias para resolver los conflictos } \\
\text { a nivel institucional o comunidad — comisión } \\
\text { de agua, presidente de comunidad, asamblea } \\
\text { de barrio-, generando certeza de ser } \\
\text { escuchado por violaciones o sanciones } \\
\text { impuestas. }\end{array}$ \\
\hline $\begin{array}{l}\text { Reconocimiento mínimo de derechos de } \\
\text { organización }\end{array}$ & $\begin{array}{l}\text { En la constitución del Estado de Tlaxcala } \\
\text { existe un reconocimiento de conformación } \\
\text { indígena, por lo cual se fomenta sus formas de } \\
\text { organización contenidas en los barrios, } \\
\text { permitiendo de esa manera su forma de } \\
\text { autoorganización. Cuenta con el apoyo de }\end{array}$ \\
\hline
\end{tabular}


Artigo original

Hegemonia - Revista Eletrônica do Programa de Mestrado em Direitos Humanos, Cidadania e Violência/Ciência Política do Centro Universitário Unieuro

ISSN: 1809-1261

UNIEURO, Brasília, número 24, Julho a Dezembro de 2018, pp. 65-92.

\begin{tabular}{|l|l|}
\hline & $\begin{array}{l}\text { recursos para cubrir el desarrollo de sus } \\
\text { necesidades. }\end{array}$ \\
\hline Entidades anidadas & $\begin{array}{l}\text { La presencia de comisiones como peldaños } \\
\text { del sistema de cargos ha permitido la atención } \\
\text { de temas relativos al agua, sin embargo, en un } \\
\text { contexto global este dejo de ser obligatoria, lo } \\
\text { que puede causar una menor interacción al } \\
\text { interior de la comunidad. }\end{array}$ \\
\hline
\end{tabular}

Elaboración propia con base en Ostrom, E. (1990). 
Artigo original

Hegemonia - Revista Eletrônica do Programa de Mestrado em Direitos Humanos, Cidadania e Violência/Ciência Política do Centro Universitário Unieuro

ISSN: 1809-1261

UNIEURO, Brasília, número 24, Julho a Dezembro de 2018, pp. 65-92.

Conclusiones

El sistema de cargos en la zona metropolitana del Valle de Puebla - Tlaxcala y de manera particular en el municipio de San Pablo del Monte, Tlaxcala, ha sido una forma de organización social que permite la acción colectiva, toda vez que permite la integración de los ciudadanos en la resolución de problemas al interior de los barrios. Esta forma de organización tradicional ha permeado a lo largo del tiempo en el imaginario colectivo, el cual se ha adecuado a cambios ocurridos en el territorio, tanto en los aspectos sociales y económicos. Asimismo, se ha mantenido como un elemento constitutivo de identidad colectiva a raíz de la interacción constante en espacios que tienen como centro en común la adoración a un santo patrono, espacios dentro de los cuales, las decisiones tomadas deberán orientarse a influir a la vida en comunidad. En este sentido se observan las prácticas de manejo y gestión de los recursos de la comunidad, a partir de lazos de colaboración y apoyo mutuo, esto como parte de las prácticas rituales de la comunidad, y ha generado éxito en su modelo de gestión, además sirviendo de apoyo para el mantenimiento del mismo.

En el caso expuesto se muestra que la acción colectiva del barrio se origina al verse en una situación de escases y problemas de manejo del agua potable, para lo cual se han basado de las dinámicas internas y los lazos generados por medio del sistema de cargos, derivando en la atención del agua con éxito, esto en contrastante con las características que analizan los modelos de gestión de larga duración de Ostrom, E. (1990) y Rivera et al (2016) que colocan a dicha institución en un modelo frágil de gestión. Por el contrario, las características de la administración generada por medio del sistema de cargos han mostrado un resultado satisfactorio, y de esa manera ha influido en la cohesión de los habitantes. Dicho modelo de gestión basado en un recurso de uso común administrado como un comité que forma parte de un sistema de cargos de la comunidad se puede observar como una forma de autogestión de recursos alterno a los modelos de mercado y de gestión pública. 
Artigo original

Hegemonia - Revista Eletrônica do Programa de Mestrado em Direitos Humanos, Cidadania e Violência/Ciência Política do Centro Universitário Unieuro

ISSN: 1809-1261

UNIEURO, Brasília, número 24, Julho a Dezembro de 2018, pp. 65-92.

\section{BIBLIOGRAFIA}

Bauman, Z. La globalización: consecuencias humanas. México: Fondo de Cultura Económica, 2008.

Bobbio, N. El futuro de la democracia. Mexico: Fondo de cultura económica. 2010.

Bonfil, G. Cholula. La ciudad sagrada en la era industrial. Ciudad de México, México: Universidad Nacional Autónoma de México,1973.

Borja, J. La ciudad es el espacio público. En P. Ramírez Kurí, Espacio público y reconstrucción de ciudadanía. México: FLACSO - Miguel Angel Porrua, pp. 59 - 88, 2003.

Bresser, C y Cunill, N. Entre o Estado e o mercado:o público não-estatal. En L. C. Bresser Pereira, \& N. Cunill Grau, ( Coord), O Público não-estatal na reforma do Estado. Rio de Janeiro: Fundação Getulio Vargas, Pp. 15 - 50, 1999.

Espinosa, O. Sociedad y agua en Zacualpan de amilpas. Ciudad de México, México: Centro de Estudios para el Desarrollo Rural Sustentable y la Soberanía Alimentaria.

Hall, R, Organizaciones, estructura y proceso. Bogotá, Colombia: Prentice/Hall. 1996.

Held, D. La democracia y el orden global: del Estado moderno al gobierno cosmopolita . Madrd, España: Paidos. 1997.

— Modelos de democracia. (T. Alberto, \& A. Gómez Cedillo, Trads.) Madrid, España: Alianza. 2001.

Hirschmann, O. El avance de la colectividad. Experimentos populares en América Latina. México: Fondo de Cultura Económica, 1986. Interés público y acción pública. México: Fondo de Cultura Económica, 1986.

Korsbaek, L. Introducción al Sistema de Cargos. Estado de México, México: UAEM, 1996.

Licona, E. Producción de imagimarios urbanos. Dibujos de un barrio. Ciudad de Puebla: BUAP, 2003

Licona, E., Gámez, A, y Villalobos L. Hacia una definición socioculturalterritorial del valle Puebla Tlaxcala. Puebla: BUAP. 2016. 
Artigo original

Hegemonia - Revista Eletrônica do Programa de Mestrado em Direitos Humanos, Cidadania e Violência/Ciência Política do Centro Universitário Unieuro

ISSN: 1809-1261

UNIEURO, Brasília, número 24, Julho a Dezembro de 2018, pp. 65-92.

Montero G, I. Matlalcueye, el volcan del alma Tlaxcalteca. México: Gobierno del Estado de Tlaxcala. 2012.

Mouffe, C. El retorno de lo político. Madrid, España: Paidos, 1999. La paradoja democrática. Barcelona: Paidos, 2003.

Nutini, H. y Barry, I. Los pueblos de babla nábuatl de la región de Tlaxcala y puebla. Ciudad de México, México: Instituto Nacional Indigenista. 1974

Nutini, H y Bell, B. Parentesco ritual: Estructura y evolución histórica del sistema de compadrazgo en la Tlaxcala rural. Ciudad de México, México: Fondo de cultura Económica, 1989

Ostrom, E. El gobierno de los bienes comunes, evolución de las instituciones de acción colectiva. Ciudad de México, México: UNAM-FCE. 2000

Pettit, P. Republicanismo. Una teoría sobre la libertad y el gobierno. (T. Domenech, Trad.) Barcelona, España: Paidos. 1999

Portal, M. Ciudadanos desde el Pueblo. Ciudad de México, México: Dirección general de culturas populares/ UAM. 1997.

Prisco, G. Raíces de la religiosidad popular, Tlaxcala, México: PACMYC. 2016

Recasens, L. Tratado general de Filosofía del Derecho. Ciudad de México, México: Porrúa, 1983

Rivera, J. Análisis socio- ecológico del servicio de agua potable en San Pablo del Monte, Tlaxcala. San Pablo Apetitlán, Tlaxcala: El Colegio de Tlaxcala, 2016.

Sassen, S. Territorio, autoridad y derechos. De los ensamblajes medievales a los ensamblajes globales. (M. V. I. Rodil, Trad.) Madrid, España: Katz. 2013.

Tamayo, S. La ciudad y la producción del espacio ciudadano. En L. Álvarez Enríquez, Ciudadanía y nuevos actores en grandes ciudades. México:Universidad Nacional Autónoma de México, Universidad Autónoma Metropolitana - I, Juan Pablos Editor. Pp.. 263 - 290, 2016

Somuano, M. Sociedad civil organizada y democracia en México, Ciudad de México, México: Colegio de México, 201. 
Artigo original

Hegemonia - Revista Eletrônica do Programa de Mestrado em Direitos Humanos, Cidadania e Violência/Ciência Política do Centro Universitário Unieuro

ISSN: 1809-1261

UNIEURO, Brasília, número 24, Julho a Dezembro de 2018, pp. 65-92.

Fuentes de sitios web

CONAGUA “Estadística del agua en México”. Ciudad de México, 2016, México: Secretaria de Medio Ambiente y Recursos Naturales.

González de la Fuente, Iñigo "Comunidad, sistema de cargos y proyecto social. Una propuesta analítica de sociedades locales en México", En Revista de Antropología Iberoamericana, (Vol. 6), (Núm. 1) Madrid, España, Ene-Abr 2011. (pp. 81-107), Recuperado de: http://www.redalyc.org/articulo.oa?id=62321332005 Fecha de consulta: 13/03/17.

Hardin, G. "La tragedia de los comunes" (1968, Horacio Bonfil, Trad.), En gaceta ecología, Instituto Nacional de Ecología, Nol. 62), (Núm. 37) Ciudad de México, México, 1995 (pp. 1243 1248),

Recuperado de: http://www.dgcft.sems.gob.mx/archivo_s/Garret_Hardin_La\%20tragedia_de_los_co munes.pdf. Fecha de consulta: 26/06/17.

Pulido, S. "Las diferentes aproximaciones al estudio de los barrios en las ciencias sociales", En Revista Investigación y Desarrollo, (vol. 24), (núm. 2) Universidad de Barranquilla, Colombia, 2016, (pp. 411-443), Recuperado de: http://www.redalyc.org.

Rivera, J., Hernández, M., Ocampo, I., Ramírez, A. Factores condicionante de la buena gestión del servicio de agua potable en doce comunidades del altiplano mexicano. En Agua y Territorio, (Núm. 9), Universidad de Jaén, España, 2017, (pp.109-116), Recuperado de: https://revistaselectronicas.ujaen.es/index.php/atma/article/view/3481 Fecha de consulta: 12/09/17.

Legislación

Ley Municipal del Estado de Tlaxcala

Constitución Política del Estado Libre y Soberado del Estado de Tlaxcala 